\title{
ЦИТ: ua117-049
}

DOI: $10.21893 / 2415-7538.2016-05-1-049$

УДК 371.1.

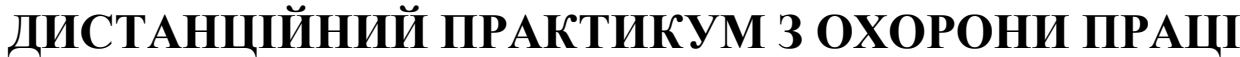

Палагута В.M.

Одеський національний морський університет,

Одеса, Мечнікова 34, 65029

Palaguta V.M.

DISTANCE PRACTICAL TRAINING ON OCCUPATIONAL SAFETY

Odessa National Maritime University,

Odessa, Mechnikova 34, 65029

Анотація. В роботі пропонується методологічний підхід до проведення лабораторного практикуму як елемента дистаниійного курсу, сформованого за допомогою системи Моодlе або в ході традиційного лабораторного практикуму без використання паперових методичних вказівок.

Ключові слова: дистанційне навчання, лабораторний практикум, відеоурок, тестування, методологічний підхід.

Abstract. In this paper we offered a methodological approach to practical training as a part of the distance learning provided by the Moodle-system or as a part of the traditional training without the paper methodological instructions.

Key words: distance learning, practical training, video-lesson, testing, methodological approach.

\section{Вступ.}

Дистанційне навчання - нова прогресивна форма підготовки, що знайшла широке поширення на Заході і останнім часом активно запроваджується в практику вітчизняних вищих навчальних закладів.

Головною перевагою дистанційного навчання, на нашу думку, є те, що студент в якості дистанційного курсу отримує повний і безпосередній доступ до інформації з даного предмета. Відтепер він $є$ незалежним від бібліотеки, методичного кабінету, розкладу консультацій і може втамовувати спрагу до знань в зручний для себе час і в зручному місці.

Дистанційний курс може успішно використовуватись і при традиційних формах навчання - заочній та стаціонарі. Єдиною умовою цього є належна мотивація студента.

Специфічним елементом дистанційного курсу $\epsilon$ лабораторна або практична робота, адже вони передбачають не тільки засвоєння знань, а й набуття навичок використання лабораторного обладнання, інструментів, практичної роботи певного напрямку. Тому концепція дистанційного навчання передбачає виконання лабораторних та практичних робіт безпосередньо у навчальному закладі під час сесії, а дистанційною залишає лише підготовку до них.

Це, в свою чергу, ставить питання про форму подання матеріалу для підготовки до лабораторного практикуму. Першим кроком тут є електронна версія методичних вказівок і контрольний тест. Дана робота, проте і на нашу 
думку, пропонує більш зручну для студента форму.

Іншим мотивом пропонованої розробки явилось те, що останнім часом позначилась тенденція до відмови (з різних причин) від паперових методичних вказівок. Читання ж електронного тексту, особливо це стосується навчальнометодичних документів великого обсягу, $\epsilon$ невдячною справою. Адже методичний документ не можна читати як оповідання - в одному напрямку. Тут необхідно багаторазово повертатись до вже прочитаного, звертатись до змісту, таблиць, малюнків, графіків. Це вимагає структуризації матеріалу на відносно невеликі порції у відповідності до логіки їхнього призначення.

\section{Основний текст.}

Вимогам, що викладено вище, задовольняє комплекс гіпертекстових документів, об'єднаних в єдине ціле за допомогою гіперпосилань. Цей підхід до подання матеріалу представлено тут на прикладі лабораторної роботи з курсу охорони праці: «Дослідження мікроклімату виробничих приміщень».

До складу комплексу входять такі документи:

- Зміст;

- Загальні положення;

- Прилади та методи дослідження;

- Відеоурок;

- Контрольні запитання;

- Протокол;

- Порядок виконання роботи;

- Довідкові матеріали.

На рис. 1 представлено скрін-шот документа під назвою «Зміст», окремі строки якого $є$ гіперпосиланнями на решту документів.

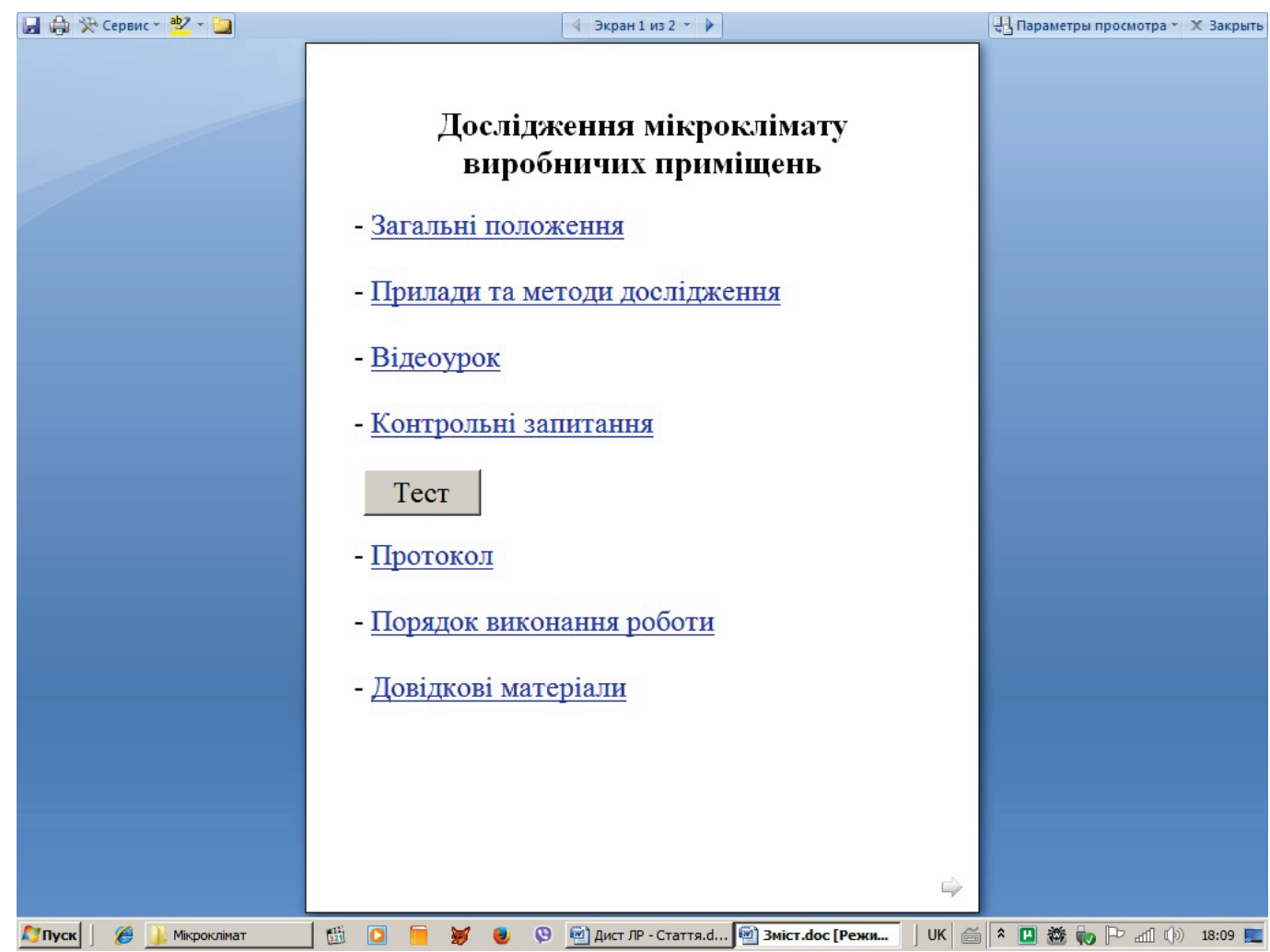

Рис. 1. Документ «Зміст» 
Для прикладу на рис. 2 представлено скрін-шот фрагмента документа «Прилади та методи дослідження».

Гіперпосилання «Відео-урок» дає можливість студенту продивитись відеозапис практичної частини роботи, тобто процес підготовки приладів та проведення вимірювань параметрів мікроклімату.

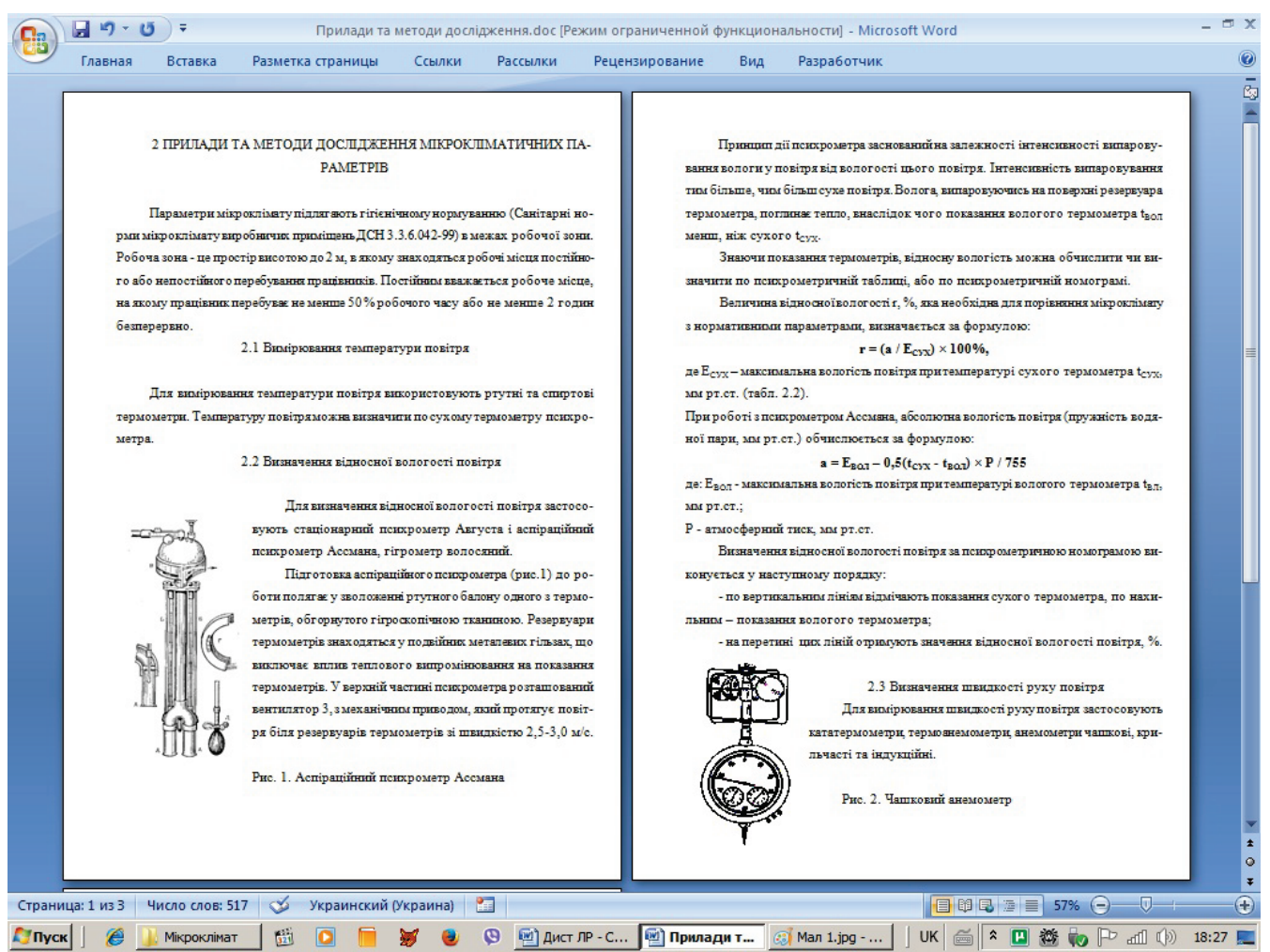

Рис. 2. Документ «Прилади та методи дослідження»

На рис. 3 представлено скрін-шот документа «Контрольні запитання», який сам $є$ гіпертекстовим. Кожне запитання являє собою гіперпосилання на відповідний абзац того чи іншого документа, який побіжно містить відповідь. Як видно на рисунку при наведенні курсору на запитання у спливаючій підказці з'являється коротка відповідь на нього.

Крім цих контрольних запитань, що служать для самоперевірки документ «Зміст» містить також програмовану кнопку «Тест», натискування якої викликає екранну форму, що служить для послідовного виведення на екран п’ятнадцяти тестових питань (рис. 4). Після відповіді на питання студент отримує оцінку за стобальною шкалою, на підставі якої може прийматись рішення про готовність студента до практичної частини роботи.

Програмний код тесту написано, зрозуміло, на Visual Basic for Applications, який при наявності навичок з програмування може бути легко модифікований для будь-якої іншої лабораторної чи практичної роботи.

Зміст документів «Протокол», «Порядок виконання роботи» та «Довідкові матеріали» не потребує пояснень.

Представлений методичний підхід успішно апробовано в ході лабораторного практикуму з охорони праці. 


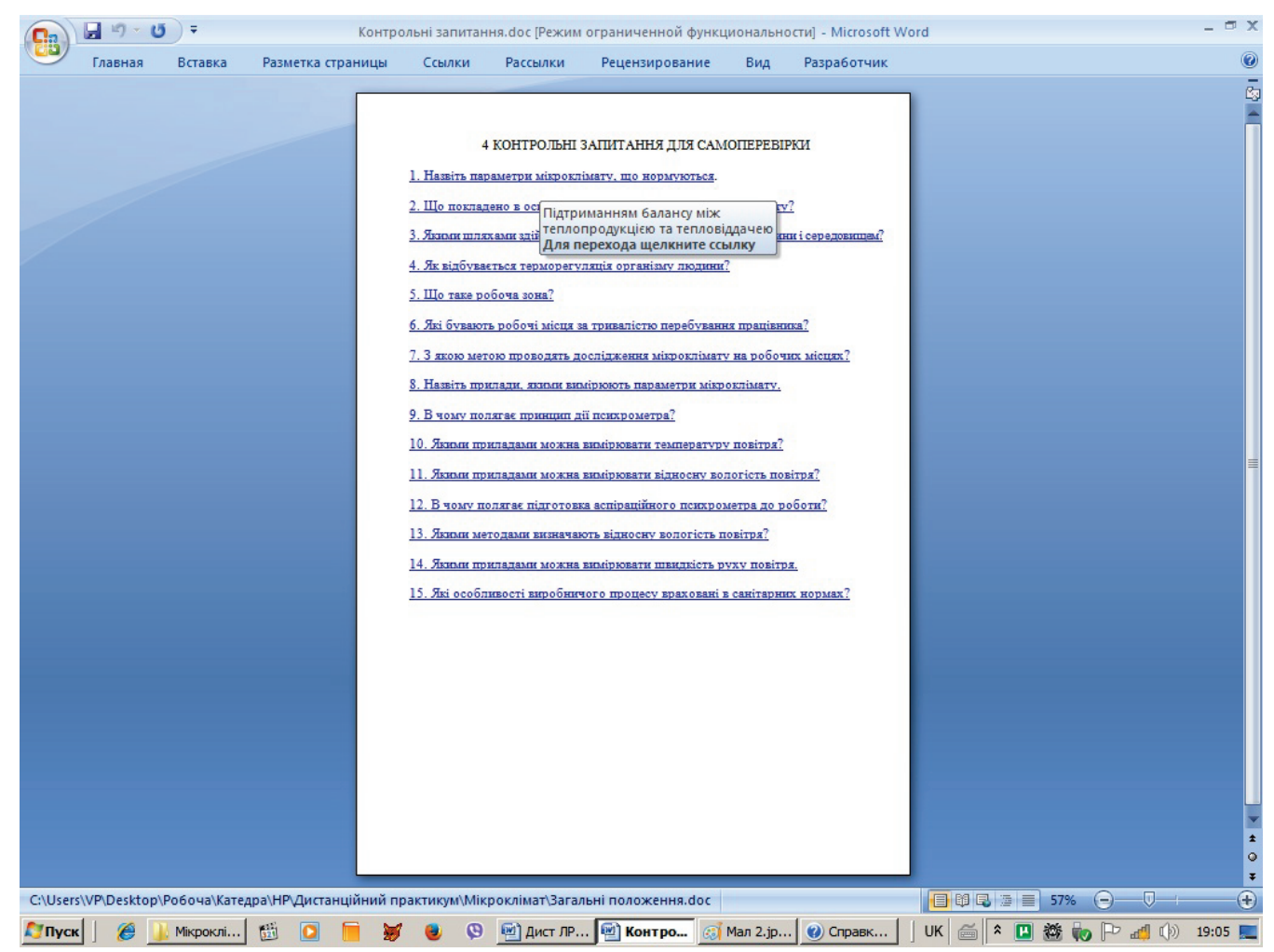

Рис. 3. Документ «Контрольні запитання»

Рис. 4. Екранна форма «Тест»

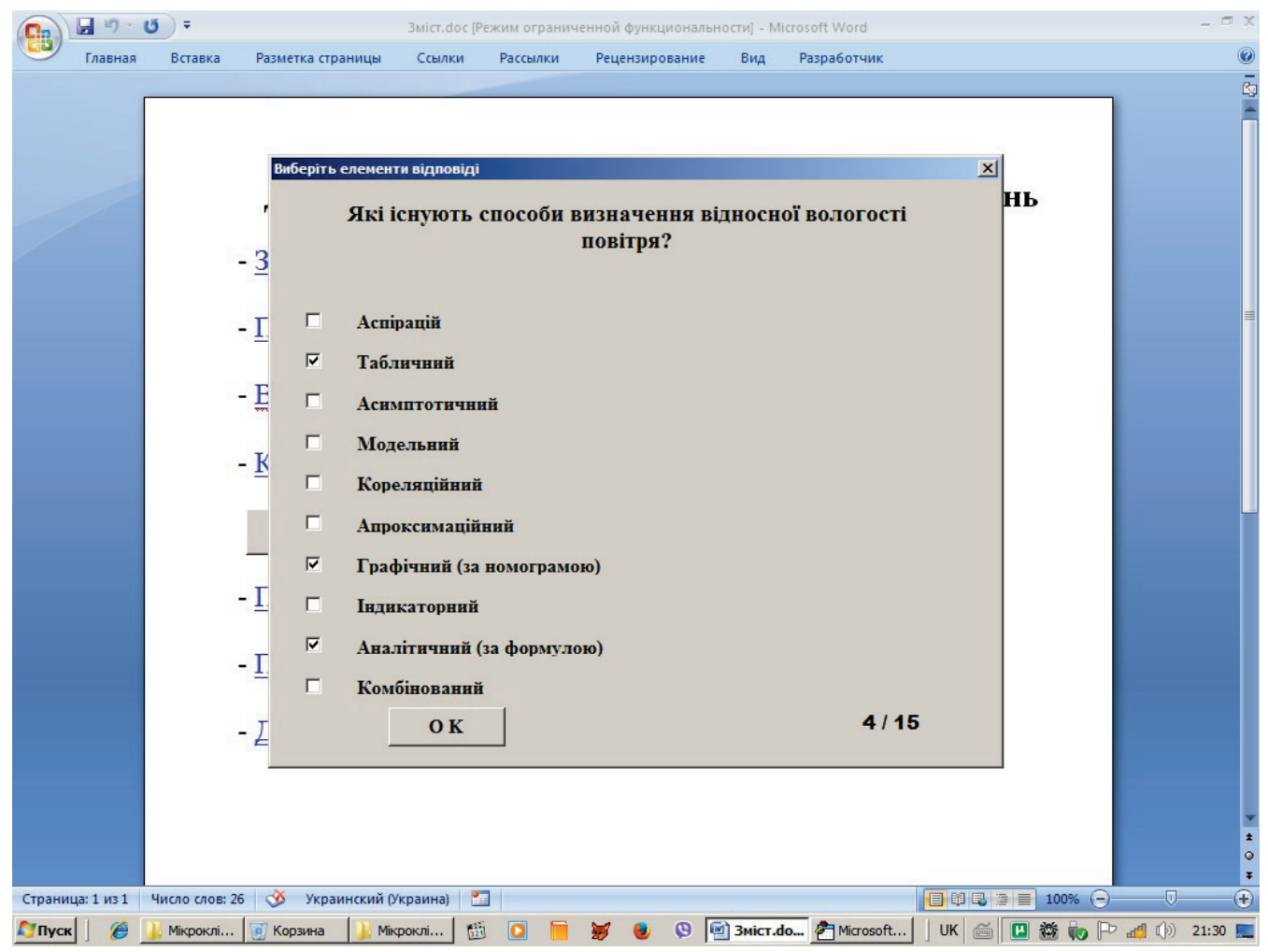

Всі вище описані методичні документи (текстові документи, включаючи програмний код, а також відео-файл) можна завантажити 3 Dropbox за посиланням:

https://www.dropbox.com/sh/q66agvcq5b4s0tu/AABSoHFXG3urv4XOLoeQdh53a? $\mathrm{dl}=0$ 